\title{
Women with Heart Failure Are at High Psychosocial Risk: A Systematic Review of How Sex and Gender Influence Heart Failure Self-Care
}

\author{
Jody R. Thomas and Alexander M. Clark \\ Faculty of Nursing, 3rd Floor Clinical Sciences Building, University of Alberta, Edmonton, Alberta, Canada T6G $2 G 3$ \\ Correspondence should be addressed to Jody R. Thomas, jthomas2@ualberta.ca
}

Received 20 November 2010; Revised 10 January 2011; Accepted 14 January 2011

Academic Editor: Dirk Westermann

Copyright (C) 2011 J. R. Thomas and A. M. Clark. This is an open access article distributed under the Creative Commons Attribution License, which permits unrestricted use, distribution, and reproduction in any medium, provided the original work is properly cited.

To improve patient support, it is important to understand how people view and experience Heart Failure (HF) self-care. This systematic review of qualitative studies included all published studies that examine the influence of sex and gender on HF self-care. A systematic search was done for papers (1995-2010) indexed in Ovid MEDLINE, Ovid Medline, Ovid EMBASE, Ovid PsycINFO, CSA Sociological Abstracts, OVID AARP Ageline, EBSCO Academic Search Complete, EBSCO CINAHL, EBSCO SocINDEX, ISI Web of Science: Social Sciences Citation Index and Science Citation Index Expanded, and Scopus. After screening of 537 citations, six qualitative studies identified that differences existed in perceptions of symptoms with women having less family involvement and psychosocial support around self-care. Moreover, women had considerably more negative views of the future, themselves and their ability to fulfill social self-care roles. Women with HF represent a highly vulnerable population and need more support for psychosocial wellbeing and self-care.

\section{Introduction}

Due to ageing populations and increased survival rates from myocardial infarction, Heart Failure (HF) is now at epidemic levels in high-income countries $[1,2]$. As a result, the costs of caring for people with HF are very high and rising. Over past decades, a primary strategy in reducing the personal and cost-related HF burden has been to promote the use of evidence-based medication prescribing [3-5]. However, over the last 5 years, there has been a growing recognition that to reduce the HF burden, it is vital to also address HF self-care [6-15]; that is, "the decisions and strategies undertaken by the individual in order to maintain life, healthy functioning and wellbeing" [16]. After being comparatively neglected for many years, self-care is now recognized as a "cornerstone" of effective HF management $[9,11]$.

Effective HF self-care improves the performance of the heart, reduces the demands of the body on the heart, and promotes general wellbeing. Evidence to support the importance of self-care in each of these areas has improved vastly over recent decades [15]. There is now strong evidence from large randomized trials and cohort studies that mortality, morbidity, and symptoms can be improved in key self-care domains through

(i) consumption of key medications [17, 18],

(ii) behavioural/lifestyle management (including smoking cessation, and salt, fluid and weight management) $[1,15,19]$,

(iii) timely use of health services [1], regular physical activity and good social relationships $[1,15]$.

Self-care of HF is important because the vast majority of ongoing care is undertaken by the person with HF and their caregiver(s) in the home-outside of the direct presence, supervision, or support of the health professional in a healthcare setting $[9,11]$. Recognition of the importance of self-care has been made in recent clinical guidelines $[1,15,19-22]$. Although recent research on self-care and its determinants has recognized a number of influential 
factors (including age, knowledge, coping skills, confidence, cognition) [12], the influence of sex and gender on HF self-care is not well understood [23]. To increase our understanding of the influence of sex and gender on HF selfcare, we reviewed existing qualitative studies of self-care in HF patients. These studies specifically contained data on the influence of sex and gender on self-care practices.

\section{Materials and Methods}

With the definition of HF self-care guiding the paperand the perception of HF self-care as a complex process, qualitative research studies were selected for inclusion. Qualitative studies have been used extensively in health research to understand user approaches and behaviours [24]. Qualitative approaches do not presuppose the topics or factors that will be identified in a research study as influencing self-care. As such, qualitative methods are used to inform the understanding of complex phenomena prior to quantitative research. A qualitative systematic paper is used to synthesize findings from similar qualitative studies $[25,26]$. It has been used previously to examine patients' reactions and experiences of HF [27].

Sex was defined in the review as "the classification of living things, generally as male or female according to their reproductive organs and functions assigned by the chromosomal complement" [28]. Gender was defined as the, distinct and individual properties of men and women that are "expressed through the values they hold, their psychosocial characteristics, and ultimately their behaviours" ([29] page 275]). Gender also has interactive or contingent dimensions of social identity; individual properties of masculinity or femininity are elicited from men and women in some social contexts, but not others [30, 31].

2.1. Inclusion Criteria. The search strategy involved general and specific terms in relation to HF. To be included in the review, studies had to include, adults over 18 years of age, be in English, men only, women only or mixed-sex studies that specifically explored the influence of gender or sex using qualitative or mixed (qualitative and quantitative) methods. The search included studies using different qualitative methodologies (including grounded theory, interpretive descriptive, and ethnography) and various techniques for data collection (including interviews and focus groups). Studies that contained data for people with coronary heart disease were excluded because these populations have different self-care needs compared to HF patients. Surveys were also excluded as these studies do not constitute qualitative research as conventionally defined.

A search was done for studies published from 1995 to 2010 that were indexed in Ovid MEDLINE, Ovid Medline, Ovid EMBASE, Ovid PsycINFO, CSA Sociological Abstracts, OVID AARP Ageline, EBSCO Academic Search Complete, EBSCO CINAHL, EBSCO SocINDEX, ISI Web of Science: Social Sciences Citation Index and Science Citation Index Expanded and Scopus. Over 110 keywords were used around heart failure and self-care (e.g., heart, self-manage*) and relevant research methods (e.g., semistructured, interview, narrative methods). Additional studies were identified from reference lists.

2.2. Literature Reviewing Process. Quality of the studies meeting the inclusion criteria was independently assessed using the Critical Appraisal Skills Programme (CASP) tool for qualitative research [32] — a valid tool for the assessment of quality in qualitative research [33]. Data extraction was undertaken by the primary author for each paper and checked by the second author. Data were extracted on the focus of the study, the population (i.e., patients, family/caregivers, health professionals), sample (i.e., men only, women only, mixed), type of sampling (i.e., convenience, purposive, theoretical, other), number and age of the sample, sample setting (i.e., country) and the method/approach of the study (i.e., grounded theory, interpretive, mixed methods, ethnography, critical theory phenomenology, etc.) and data collection methods (i.e., face to face/telephone interviews). Quality was assessed independently using the CASP tool with disagreements resolved by consensus. The metaethnographic approach [34] was used to synthesize findings from the studies. This involved the primary author reading each study to identify, based on the team's approach to self-care, the main self-care needs of patients/lay caregivers and links between different needs and age. Matrices were developed to record these first order interpretations $[26,35]$. These represent the main findings of each study as presented by the participants in the studies $[33,36]$. The details of each study in terms of setting and quality were also extracted and taken into account at this stage. Stage two (second-order coding) involved the researchers examining the relationships between concepts identified in the findings from the matrices [37]. Second-order interpretations of common or reoccurring concepts were sought and interpreted in the context of study quality and setting [36]. For the third stage (synthesis), the main concepts identified during the second stage (second order interpretations) were used to reinterpret each paper and reconsider the relationships between the papers. The results of this synthesis will be the findings of the review.

\section{Results}

After initial screening of 537 studies, 78 papers were retrieved, and reviewed in full. From these studies, six studies were identified that used qualitative methods containing or examined themes related to gender differences in HF patient's perceptions and experiences (Table 1). These studies recruited patients with a wide range of ages (35 to 95 years). Sample sizes ranged from 4 to 32 with a total of 61 women and 31 men. Only one study [38] had a sample of men only. Four studies recruited women-only samples [39-42]. Two studies from Sweden used a "phenomenographic" approach $[38,39]$, two studies from the United States of America (USA) used a "phenomenology" approach [40, 41], and two studies (USA and Australia) used "mixed methods" [42, 43].

All the included studies used semistructured interviews as a method of data collection, and recruited patients $\geq 18$ 
TABLE 1: Summary of included studies.

\begin{tabular}{|c|c|c|c|c|}
\hline $\begin{array}{l}\text { Author, year, and } \\
\text { country }\end{array}$ & Main aim & Data collection & Sampling criteria & Sample and gender \\
\hline $\begin{array}{l}\text { Mårtensson et al., } \\
\text { (1997) (Sweden) [38] }\end{array}$ & $\begin{array}{l}\text { From a nurses perspective, } \\
\text { explore how male patients } \\
\text { with CHF conceive their } \\
\text { life situation. }\end{array}$ & $\begin{array}{l}\text { One open and } \\
\text { semi-structured interview. } \\
\text { Time elapse between Dx } \\
\text { and interview: } 5 \text { patients: } \\
\text { 2-6 months } 3 \text { patients: } \\
7-12 \text { months } 2 \text { patients: } \\
\text { 13-18 months } 2 \text { patients: } \\
\text { 19-24 months. }\end{array}$ & $\begin{array}{l}\text { Male patient's from medical clinic } \\
\text { with CHF. Variables on the log list } \\
\text { were, age, month/year of diagnosis, } \\
\text { NYHA classification, aetiology, } \\
\text { education, civil status, occupation. }\end{array}$ & $n=12$ Male \\
\hline $\begin{array}{l}\text { Mårtensson et al., } \\
\text { (1998) (Sweden) [39] }\end{array}$ & $\begin{array}{l}\text { From a nurses perspective } \\
\text { how female patients with } \\
\text { CHF conceive their life } \\
\text { situation. }\end{array}$ & $\begin{array}{l}\text { One open, semi-structured } \\
\text { interview Time elapse } \\
\text { between Dx and interview: } \\
2 \text { patients: } 2-6 \text { months; } 4 \\
\text { patients; } 7-12 \text { months; } 3 \\
\text { patients: } 13-18 \text { months; } 3 \\
\text { patients: } 19-24 \text { months. }\end{array}$ & $\begin{array}{l}\text { Female patients from a medical } \\
\text { clinic, between ages of } 65 \text { and } 83 \\
\text { years. Variables on the log list were, } \\
\text { age, month/year of diagnosis. } \\
\text { NYHA classification, aetiology, } \\
\text { education, civil status, and } \\
\text { occupation. }\end{array}$ & $n=12$ Female \\
\hline $\begin{array}{l}\text { Rhodes, and Bowles } \\
\text { (2002) (USA) [40] }\end{array}$ & $\begin{array}{l}\text { Examine and describe the } \\
\text { experience of older women } \\
\text { living with NYHA class II } \\
\text { HF. }\end{array}$ & $\begin{array}{l}\text { Four semi-structured } \\
\text { interviews, }<1 \text { hour each. }\end{array}$ & $\begin{array}{l}\text { Female patients between ages of } \\
60-90 \text { years who self-reported they } \\
\text { had been Dx by their cardiologist } \\
\text { with NYHA stage II HF or } \\
\text { identified by health professionals } \\
\text { and through presentations at } \\
\text { retirement centre's, Caucasian, } \\
\text { diagnosed with HF from } 2 \text { to } 10 \\
\text { years. }\end{array}$ & $n=5$ Female \\
\hline $\begin{array}{l}\text { Allen et al., (2009) } \\
\text { (USA) [41] }\end{array}$ & $\begin{array}{l}\text { Explore the lived } \\
\text { experience of HF, in middle } \\
\text { aged women with NYHA } \\
\text { class III. }\end{array}$ & $\begin{array}{l}\text { Audiotape recorded, semi } \\
\text { structured telephone } \\
\text { interview. }\end{array}$ & $\begin{array}{l}\text { Convenience sample of } 4 \text { women } \\
\text { screened by case manager at } \\
\text { cardiology practice using criteria: } \\
\text { female; dx with NYHA class III HF; } \\
\geq 21 \text { years of age; verbally articulate; } \\
\text { willing to participate }\end{array}$ & $\begin{array}{l}n=4 \text { Female } \\
\text { Consecutive women } \\
\text { with class III HF } \\
\text { were recruited until } \\
\text { redundancy in } \\
\text { description was } \\
\text { obtained. }\end{array}$ \\
\hline $\begin{array}{l}\text { Gary, (2006) (USA) } \\
{[42]}\end{array}$ & $\begin{array}{l}\text { Examine the frequency of } \\
\text { self-care practices in } \\
\text { women with DHF and } \\
\text { describe the demographic } \\
\text { and clinical characteristics } \\
\text { that affect self-care } \\
\text { practices in women with } \\
\text { DHF. }\end{array}$ & $\begin{array}{l}2 \mathrm{hr} \text { audio taped, semi } \\
\text { structured interview guide } \\
\text { by telephone or face to face } \\
\text { interview. }\end{array}$ & $\begin{array}{l}\text { Convenience sample of } 32 \text { women } \\
\text { Dx diastolic HF, NYHA Class II-III } \\
>50 \text { years of age at a large health } \\
\text { science center recruited by a } \\
\text { cardiologist from a study } \\
\text { comparing combined walking and } \\
\text { education program and an } \\
\text { education program only. MMSE } \\
>25 \text {, on optimal pharmacologic HF } \\
\text { therapy. }\end{array}$ & $n=32$ Female \\
\hline $\begin{array}{l}\text { Riegel, et al., (2010) } \\
\text { (Australia) [43] }\end{array}$ & $\begin{array}{l}\text { Describe HF self-care in } \\
\text { men and women and } \\
\text { identify gender-specific } \\
\text { barriers and facilitators } \\
\text { influencing HF self-care. }\end{array}$ & $\begin{array}{l}\text { Cross-sectional, } \\
\text { comparative mixed } \\
\text { methods study quantitative } \\
\text { survey and qualitative semi } \\
\text { structured narrative audio } \\
\text { taped and transcribed } \\
\text { interview, either face to face } \\
\text { or telephone. }\end{array}$ & $\begin{array}{l}\text { A } 2008 \text { cross-sectional, comparative } \\
\text { mixed methods study was reviewed } \\
\text { for in-depth interviews eliciting } \\
\text { self-care behaviors and exploring } \\
\text { barriers and facilitators of self-care. } \\
\text { From this study a purposive sample } \\
\text { of English speaking NYHA Class } \\
\text { II/III HF of } \geq 6 \text { months with a } \\
\text { MMSE score of }>24 \text {. }\end{array}$ & $\begin{array}{l}\text { Mixed } n=19(70 \% \\
\text { Male) } n=8(30 \% \\
\text { Female })\end{array}$ \\
\hline
\end{tabular}

NYHA: New York heart association; HF: heart failure; CHF: congestive heart failure; Dx: Diagnosis; SD: standard deviation; MMSE: mini mental status exam.

years of age with NYHA classifications of Class II or III. The six qualitative studies varied in methodological quality ( 2 high quality, 1 medium quality, and 2 low quality papers). The qualitative studies chosen were systematically evaluated to comprehend the influence of gender on HF patients' willingness and capacity for effective self-care. The stated foci of studies were illness experiences [38-41] or barriers and facilitators of $\mathrm{HF}$ self-care $[42,43]$. However, each used gender as a means to interpret data that resulted in similar categories/themes. These similarities not only 
identify relevant issues, they also support the value of each study and their findings.

The data from all these studies, having been organized into various themes/categories, gave adequate illustration of the different aspects of the self-care experience of men and women with HF. The qualitative research objectives covered several aspects about living with HF, including: (1) new self concept, (2) physical limitations, (3) negative emotions/losses, (4) support/deepening relationships, (5) rejuvenate/rest, (6) hope, (7) uniqueness of gender. Participants were recruited from outpatient clinics [38, 39]; professional referrals [40], unspecified healthcare settings [41], and from a previously hospitalized sample of HF patients [43].

\subsection{Synthesis}

3.1.1. Overwhelming Physical Limitations. The most overarching theme identified across the sexes in relation to HF was the overwhelming physical limitations experienced by men and women-their loss of energy, high fatigue and shortness of breath/breathlessness affected all aspects of life, including occupation, social, and recreational roles [38-43]. This occurred even when participants were not clear what was causing their symptoms, for example, some women reported difficulty in differentiating HF symptoms from their wider emotions [43].

Reductions in physical activity in the form of sitting or sleeping were used to prevent and/or alleviate symptoms in all the studies. Taking time to try and complete the activities of daily living, while accepting the fact they may not complete the task was common across sexes [38-43].

3.1.2. Changes to Social Roles and Identity. Life after a diagnosis of HF, compared to past functioning, and social roles, was seen in negative terms by both sexes. However, women viewed themselves in a range of more negative ways, including: being "handicapped", "sick", "burdensome" or "worthless" [39, 41, 42].

Fears of death, isolation, of being a burden, and struggles with depression and unhappiness over their physical limitations were common across the sexes [39-42]. However, again women experienced more negative feelings of anger and hate towards their HF $[40,41]$ and reported greater loss of hope $[41,43]$. The women worried over a lack of money, not being able to care for others or of being dependent on others $[39,40,42]$. Some women increased coping by consciously refocusing "...their mental energy in ways more productive for dealing with their HF" [40] or placed great hope in maintaining their present level of functioning $[39,42]$.

Conversely, men reported a wider range of positive and negative emotions compared to women. Some reported being more "anxious" or "fearful" both about HF [43] and its effects on their family [38]. However, in relation to the future, other men were hopeful and determined [38]. Age appeared to moderate men's emotions-with younger men being more negative about $\mathrm{HF}$ and the negative effects on life [43].
3.1.3. Social Support and Relationships. While women saw supportive relationships as being based on having someone to talk to [39-43], women in all the studies frequently reported that they did not have another close person they could rely on to even help with activities of daily living [39, $40,42,43]$. Conversely, men reported having more tangible support with family members being involved in supporting their HF self-care $[38,43]$. With the assistance of family, men had more confidence in interpreting symptoms of HF and self-care $[38,43]$.

\section{Discussion}

This paper identified that though HF has severe effects on the physical and psychosocial wellbeing of both sexes, women frequently experience more negative emotions in relation to the HF, tend to have lower confidence, poorer social and family support, and see the future as more bleak. Age and culture did appear to influence the experiences and reactions to HF in conjunction with gender and sex. Further research into these interactive effects is needed.

These patterns in women are a cause for concern because achieving effective HF self-care is difficult for both sexes. This process is complex as it requires a range of activities, skills, confidence and sustained efforts. As HF is associated with older age, women comprise more than half of the already large population with $\mathrm{HF}[44,45]$. Achieving optimal conditions for effective self-care in the large female HF population is therefore of high clinical significance.

Though people with HF tend to be at risk for poor psychosocial health with $40 \%$ having depression or depressive symptoms [46], women are particularly vulnerable to adverse psychosocial health and support. This may be because women with HF tend to have more symptoms than men $[47,48]$. However, it may also be related to the lower psychosocial and family support identified in the studies in this review or to a reluctance of men to voice being isolated or fearful. That said, there is wider evidence from observational studies that psychosocial factors are more adverse in women with HF and that these psychosocial factors not only affect wellbeing but also HF self-care [49-51].

The large size and distinctive self-care needs of the population of women with HF suggest that more gendersensitive approaches are needed for care and disease management. While supporting self-care is now recognized to be a vital part of effective disease management [11], there is as yet little appreciation or acknowledgement in clinical guidelines that women have distinct or greater needs for psychosocial support than men with HF. This paper and other evidence [49-51] indicate that women need additional support around psychosocial factors and self-care that is sensitive to elements of gender and sex.

Health professionals providing care to people with HF during the self-care management phase should be aware of the vulnerability that women can experience around psychosocial health and support. Where possible, families, partners and other lay caregivers should be mobilized to provide effective support to the women with HF not only around 
self-care but also in relation to more general psychosocial wellbeing. In addition to increasing psychosocial support, antidepressant medications should be considered for women who are suitable candidates [52].

As with most systematic reviews, this review was confined to studies that had been published. While there is a sizable body of qualitative research into HF, relatively few studies included or incorporated gender into analyses. The data in the studies contain only preliminary insights into how gender influences HF patients' willingness and capacity for effective self-care. Further research is needed into understanding the nature and influences on psychosocial factors in women with HF. The effects of contextual factors such as being married, widowed, ethnicity, living alone, years of HF experience, education, income and age on women need further exploration.

\section{Conclusions}

Patients of both sexes experience severe physical and psychosocial effects from HF. Yet, women with HF tend to have considerably more negative views of the future, themselves and their ability to fulfill social self-care roles. Women also report having less support for psychosocial wellbeing and self-care. As a highly vulnerable population, women need more and better support from health professionals, families and caregivers for psychosocial wellbeing and self-care.

\section{Acknowledgments}

Alexander M. Clark receives career awards from Alberta Innovates Health Care Solutions and the Canadian Institutes of Health Research.

\section{References}

[1] Task Force for Diagnosis and Treatment of Acute and Chronic Heart Failure 2008 of European Society of Cardiology et al., "ESC Guidelines for the diagnosis and treatment of acute and chronic heart failure 2008: the Task Force for the Diagnosis and Treatment of Acute and Chronic Heart Failure 2008 of the European Society of Cardiology," European Journal of Heart Failure, vol. 29, pp. 2388-2442, 2008.

[2] M. Jessup et al., "2009 focused update: ACCF/AHA guidelines for the diagnosis and management of heart failure in adults: a report of the American college of cardiology foundation/american heart association task force on practice guidelines: developed in collaboration with the international society for heart and lung transplantation," Circulation, vol. 119, no. 14, pp. 1977-2016, 2009.

[3] J. J. V. McMurray, "Failure to practice evidence-based medicine: why do physicians not treat patients with heart failure with angiotensin-converting enzyme inhibitors?" European Heart Journal, vol. 19, supplement, pp. L15-L21, 1998.

[4] J. G. F. Cleland, K. Swedberg, F. Follath et al., "The EuroHeart Failure survey programme-a survey on the quality of care among patients with heart failure in Europe-part 1: patient characteristics and diagnosis," European Heart Journal, vol. 24, no. 5, pp. 442-463, 2003.

[5] M. Komajda, F. Follath, K. Swedberg et al., "The EuroHeart Failure survey programme-a survey on the quality of care among patients with heart failure in Europe-part 2: treatment," European Heart Journal, vol. 24, no. 5, pp. 464474, 2003.

[6] C. Jillings, "Patients with heart failure had inadequate information about the disease and lacked the tools for optimal selfcare," Evidence-Based Nursing, vol. 7, no. 4, p. 127, 2007.

[7] V. V. Dickson, N. Tkacs, and B. Riegel, "Cognitive influences on self-care decision making in persons with heart failure," American Heart Journal, vol. 154, no. 3, pp. 424-431, 2007.

[8] S. B. Dunbar, P. C. Clark, C. Quinn, R. A. Gary, and N. J. Kaslow, "Family influences on heart failure self-care and outcomes," Journal of Cardiovascular Nursing, vol. 23, no. 3, pp. 258-265, 2008.

[9] L. S. Evangelista and M. A. Shinnick, "What do we know about adherence and self-care?" Journal of Cardiovascular Nursing, vol. 23, no. 3, pp. 250-257, 2008.

[10] D. K. Moser and J. F. Watkins, "Conceptualizing self-care in heart failure: a life course model of patient characteristics," Journal of Cardiovascular Nursing, vol. 23, no. 3, pp. 205-218, 2008.

[11] B. Riegel, "Foreword: self-care of heart failure: what is the state of the science?" Journal of Cardiovascular Nursing, vol. 23, no. 3, pp. 187-189, 2008.

[12] B. Riegel and V. V. Dickson, "A situation-specific theory of heart failure self-care," Journal of Cardiovascular Nursing, vol. 23, no. 3, pp. 190-196, 2008.

[13] A. M. Clark, C. N. Freydberg, F. A. McAlister, R. T. Tsuyuki, P. W. Armstrong, and L. A. Strain, "Patient and informal caregivers' knowledge of heart failure: necessary but insufficient for effective self-care," European Journal of Heart Failure, vol. 11, no. 6, pp. 617-621, 2009.

[14] T. Jaarsma, K. F. Årestedt, J. Mårtensson, K. Dracup, and A. Strömberg, "The European Heart Failure Self-care Behaviour scale revised into a nine-item scale (EHFScB-9): a reliable and valid international instrument," European Journal of Heart Failure, vol. 11, no. 1, pp. 99-105, 2009.

[15] B. Riegel, D. K. Moser, S. D. Anker et al., "State of the science: promoting self-care in persons with heart failure: a scientific statement from the american heart association," Circulation, vol. 120, no. 12, pp. 1141-1163, 2009.

[16] T. Jaarsma, A. Strömberg, J. Mårtensson, and K. Dracup, "Development and testing of the European Heart Failure SelfCare Behaviour Scale," European Journal of Heart Failure, vol. 5, no. 3, pp. 363-370, 2003.

[17] M. K. Davies, C. R. Gibbs, and G. Y. H. Lip, "Management: diuretics, ACE inhibitors, and nitrates," British Medical Journal, vol. 320, no. 7232, pp. 428-431, 2000.

[18] E. Lonn and R. McKelvie, "Drug treatment in heart failure," British Medical Journal, vol. 320, no. 7243, pp. 1188-1192, 2000.

[19] J. M. O. Arnold, P. Liu, C. Demers et al., "Canadian Cardiovascular Society consensus conference recommendations on heart failure 2006: diagnosis and management," Canadian Journal of Cardiology, vol. 22, no. 1, pp. 23-45, 2006.

[20] Heart Failure Society of America, Self-Care: Following your Treatment Plan and Dealing with your Symptoms, Heart Failure Society of America, St Paul, Minn, USA, 2006.

[21] Heart Failure Society of America, HFSA 2006 Comprehensive Heart Failure Practice Guideline, Heart Failure Society of America, St Paul, Minn, USA, 2006.

[22] J. M. O. Arnold, J. G. Howlett, A. Ducharme et al., "Canadian Cardiovascular Society Consensus conference guidelines on heart failure-2008 update: best practices for the transition of care of heart failure patients, and the recognition, investigation 
and treatment of cardiomyopathies," Canadian Journal of Cardiology, vol. 24, no. 1, pp. 21-40, 2008.

[23] A. C. C. Ng, H. S. P. Wong, A. S. C. Yong, and A. P. Sindone, "Impact of gender on outcomes in chronic systolic heart failure," International Journal of Cardiology, vol. 117, no. 2, pp. 214-221, 2007.

[24] C. Pope and N. Mays, "Qualitative Research: reaching the parts other methods cannot reach: an introduction to qualitative methods in health and health services research," British Medical Journal, vol. 311, no. 6996, pp. 42-45, 1995.

[25] M. Dixon-Woods and R. Fitzpatrick, "Qualitative research in systematic reviews," British Medical Journal, vol. 323, no. 7316, pp. 765-766, 2001.

[26] P. Pound, N. Britten, M. Morgan et al., "Resisting medicines: a synthesis of qualitative studies of medicine taking," Social Science and Medicine, vol. 61, no. 1, pp. 133-155, 2005.

[27] D. S. F. Yu, D. T. F. Lee, A. N. T. Kwong, D. R. Thompson, and J. Woo, "Living with chronic heart failure: a review of qualitative studies of older people," Journal of Advanced Nursing, vol. 61, no. 5, pp. 474-483, 2008.

[28] Institute of Medicine, Exploring the Biological Contributions to Human Health: Does Sex Matter? National Academy Press, Washington, DC, USA, 2001.

[29] K. M. King and H. M. Arthur, "Coronary heart disease prevention: views on women's gender-based perceptions and meanings," The Journal of Cardiovascular Nursing, vol. 18, no. 4, pp. 274-281, 2003.

[30] S. Fenstermaker and C. West, Eds., Doing Gender, Doing Difference: Inequality, Power, and Institutional Change, Routledge, New York, NY, USA, 2002.

[31] C. West and D. H. Zimmerman, "Doing gender," Gender and Society, vol. 2, no. 2, pp. 125-151, 1987.

[32] NHS Learning and Development, Critical Appraisal Skills Programme (CASP) and Evidence-Based Practice: CASP Qualitative Appraisal Tool, 2007.

[33] G. S. Feder, M. Hutson, J. Ramsay, and A. R. Taket, "Women exposed to intimate partner violence: expectations and experiences when they encounter health care professionals: a metaanalysis of qualitative studies," Archives of Internal Medicine, vol. 166, no. 1, pp. 22-37, 2006.

[34] G. Noblit and R. Hare, Meta-Ethnography: Synthesizing Qualitative Data, Sage, London, UK, 1988.

[35] N. Mays, C. Pope, and J. Popay, "Systematically reviewing qualitative and quantitative evidence to inform management and policy-making in the health field," Journal of Health Services Research and Policy, vol. 10, no. 1, pp. 6-20, 2005.

[36] N. Britten, R. Campbell, C. Pope, J. Donovan, M. Morgan, and R. Pill, "Using meta ethnography to synthesise qualitative research: a worked example," Journal of Health Services Research and Policy, vol. 7, no. 4, pp. 209-215, 2002.

[37] I. D. Graham, J. Logan, M. B. Harrison et al., "Lost in knowledge translation: time for a map?" The Journal of Continuing Education in the Health Professions, vol. 26, no. 1, pp. 13-24, 2006.

[38] J. Mårtensson, J. E. Karlsson, and B. Fridlund, "Male patients with congestive heart failure and their conception of the life situation," Journal of Advanced Nursing, vol. 25, no. 3, pp. 579586, 1997.

[39] J. Mårtensson, J. E. Karlsson, and B. Fridlund, "Female patients with congestive heart failure: how they conceive their life situation," Journal of Advanced Nursing, vol. 28, no. 6, pp. 1216-1224, 1998.
[40] D. L. Rhodes and C. L. Bowles, "Heart failure and its impact on older women's lives," Journal of Advanced Nursing, vol. 39, no. 5, pp. 441-449, 2002.

[41] J. W. Allen, C. Arslanian-Engoren, and J. Lynch-Sauer, "The lived experience of middle-aged women with New York Heart Association class III heart failure: a pilot study," Progress in Cardiovascular Nursing, vol. 24, no. 3, pp. 96-101, 2009.

[42] R. Gary, "Self-care practices in women with diastolic heart failure," Heart and Lung, vol. 35, no. 1, pp. 9-19, 2006.

[43] B. Riegel, V. V. Dickson, L. Kuhn, K. Page, and L. WorrallCarter, "Gender-specific barriers and facilitators to heart failure self-care: a mixed methods study," International Journal of Nursing Studies, vol. 47, no. 7, pp. 888-895, 2010.

[44] A. L. Pruitt, "Heart failure: it's not just for men," Critical Care Nursing Clinics of North America, vol. 20, no. 3, pp. 327-341, 2008.

[45] C. W. Yancy, G. C. Fonarow, N. M. Albert et al., "Influence of patient age and sex on deliveryof guideline-recommended heart failure care in the outpatient cardiology practice setting: findings from IMPROVE HF," American Heart Journal, vol. 157, no. 4, pp. 754-762, 2009.

[46] T. Rutledge, V. A. Reis, S. E. Linke, B. H. Greenberg, and P. J. Mills, "Depression in heart failure. A meta-analytic review of prevalence, intervention effects, and associations with clinical outcomes," Journal of the American College of Cardiology, vol. 48, no. 8, pp. 1527-1537, 2006.

[47] I. Ekman and A. Ehrenberg, "Fatigue in chronic heart failure-does gender make a difference?" European Journal of Cardiovascular Nursing, vol. 1, no. 1, pp. 77-82, 2002.

[48] V. Vaccarino, Y. T. Chen, Y. Wang, M. J. Radford, and H. M. Krumholz, "Sex differences in the clinical care and outcomes of congestive heart failure in the elderly," American Heart Journal, vol. 138, no. 5 I, pp. 835-842, 1999.

[49] S. Heo, D. K. Moser, T. A. Lennie, B. Riegel, and M. L. Chung, "Gender differences in and factors related to self-care behaviors: a cross-sectional, correlational study of patients with heart failure," International Journal of Nursing Studies, vol. 45, no. 12, pp. 1807-1815, 2008.

[50] M. L. Chung, D. K. Moser, T. A. Lennie et al., "Gender differences in adherence to the sodium-restricted diet in patients with heart failure," Journal of Cardiac Failure, vol. 12, no. 8, pp. 628-634, 2006.

[51] B. González, J. Lupón, T. Parajón et al., "Nurse evaluation of patients in a new multidisciplinary Heart Failure Unit in Spain," European Journal of Cardiovascular Nursing, vol. 3, no. 1, pp. 61-69, 2004.

[52] C. M. O'Connor, W. Jiang, M. Kuchibhatla et al., "Antidepressant use, depression, and survival in patients with heart failure," Archives of Internal Medicine, vol. 168, no. 20, pp. 2232-2237, 2008. 


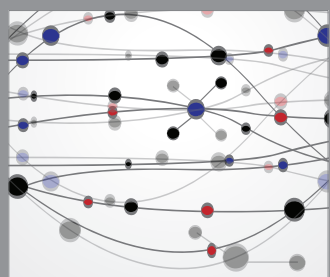

The Scientific World Journal
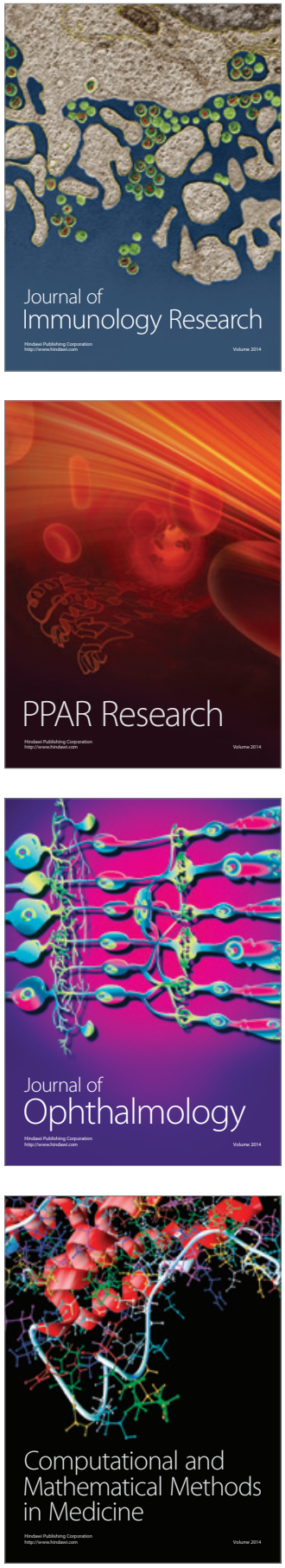

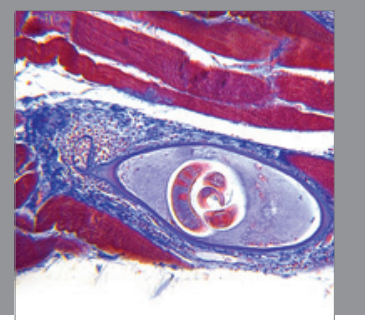

Gastroenterology

Research and Practice
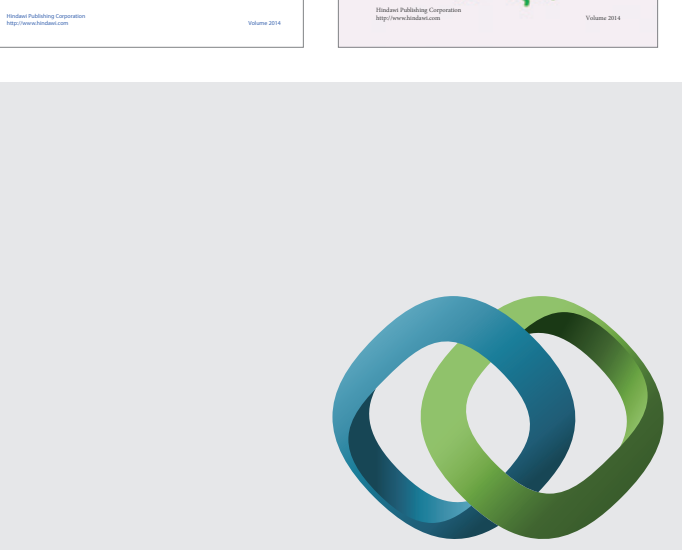

\section{Hindawi}

Submit your manuscripts at

http://www.hindawi.com
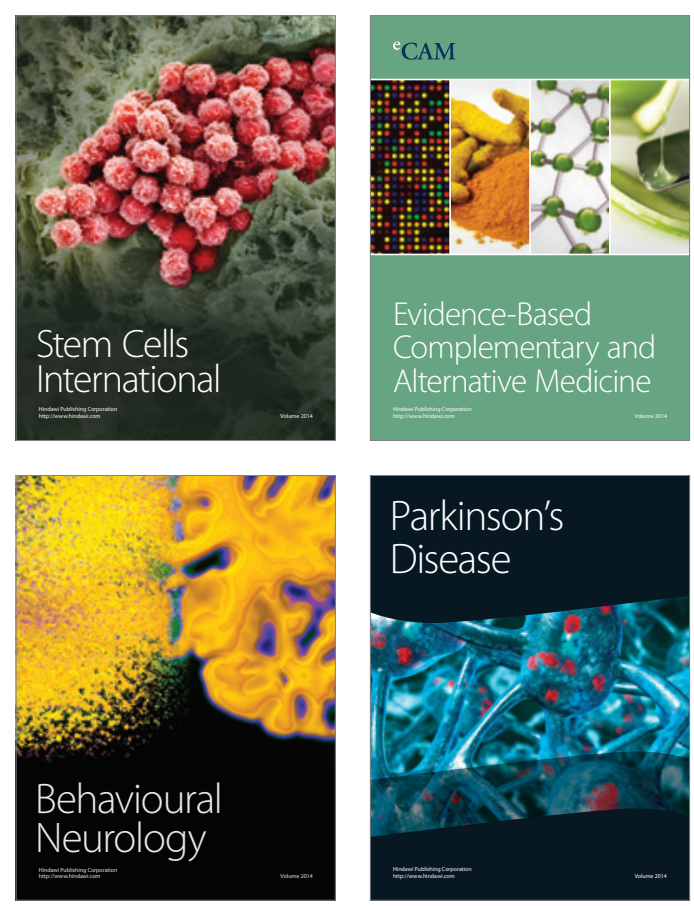

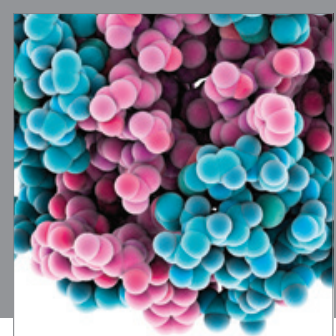

Journal of
Diabetes Research

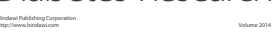

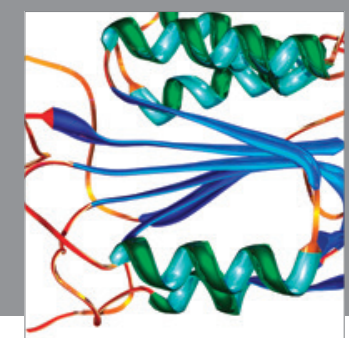

Disease Markers
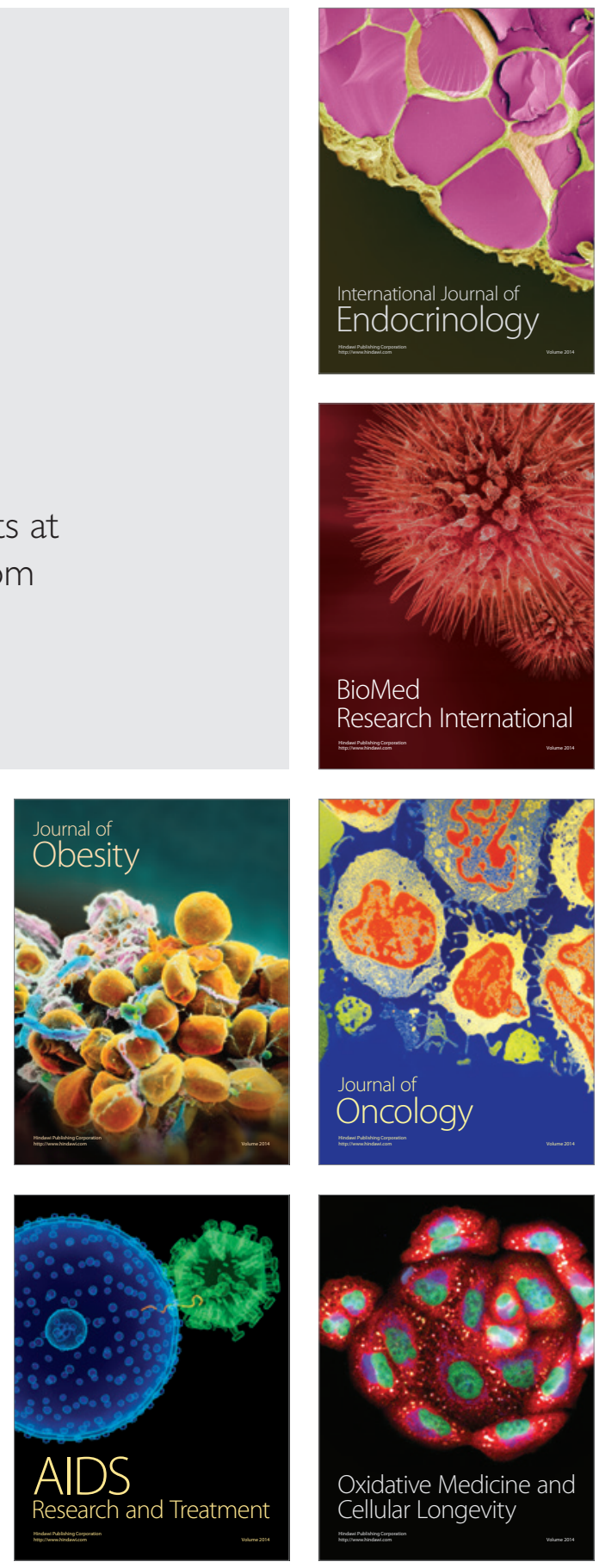